\title{
Studies on changes of estimated breeding values of U.S. Holstein bulls for final score from the first to second crop of daughters
}

\author{
V. K. R. Koduru • S. Tsuruta • M. Lukaszewicz • \\ I. Misztal • T. J. Lawlor
}

Received: 4 September 2009 /Revised: 29 September 2010/Accepted: 8 October 2010 /Published online: 23 November 2010

(C) The Author(s) 2010. This article is published with open access at Springerlink.com

\begin{abstract}
The purpose of this study was to find ways of reducing changes of sire predicted transmitting ability for type's final scores (PTATs) from the first to second crop of daughters. The PTATs were estimated from two datasets: D01 (scores recorded up to 2001) and D05 (scores recorded up to 2005). The PTAT changes were calculated as the difference between the evaluations based on D01 and D05. The PTATs were adjusted to a common genetic base of all evaluated cows born in 1995. The single-trait (ST) animal model included the fixed effects of the herd-year-seasonclassifier, age by year group at classification, stage of lactation at classification, registry status of animals, and additive genetic and permanent environment random effects. Unknown parent groups (UPGs) were defined based on every other birth year starting from 1972. Modifications to the ST model included the usage of a single record per cow, separate UPGs for first and second crop daughters, separate UPGs for sires and dams, and
\end{abstract}

V. K. R. Koduru $\cdot$ S. Tsuruta $\cdot$ M. Łukaszewicz $\cdot$ I. Misztal

Department of Animal and Dairy Science, University of Georgia,

Athens, GA 30602, USA

V. K. R. Koduru

Acharya N. G. Ranga Agricultural University Rajendranagar,

Hyderabad 500030 Andhra Pradesh, India

M. Łukaszewicz ( $\square)$

Institute of Genetics and Animal Breeding,

Polish Academy of Sciences,

Jastrzębiec,

05-552, Wólka Kosowska, Poland

e-mail: m.lukaszewicz@ighz.pl

T. J. Lawlor

Holstein Association USA, Inc.,

1 Holstein Place,

Brattleboro, VT 05302, USA deepened pedigrees for dams with missing phenotypic records. Also, the multiple-trait (MT) model treated records of registered and grade cows as correlated traits. The mean PTAT change, for all of the sires, was close to zero in all of the models analyzed. The estimated mean PTAT change for 145 sires with 40 to 100 first crop and $\geq 200$ second crop daughters was $-0.33,-0.20,-0.13,-0.28$, and -0.12 with ST, only first records, only last records, updated pedigrees, and allowing separate parent groups (PGs) for sires and dams after updating the pedigrees, respectively. The percentages of sires showing PTAT decline were reduced from 74.5 (with ST) to 57.3 by using only the last records of cows, and to 56.4 by allowing separate UPGs for sires and dams after updating the pedigrees. Though updating of the pedigrees alone was not effective, separate UPGs for sires together with additional pedigree was helpful in reducing the bias.

Keywords Breeding value $\cdot$ Final score $\cdot$ Fluctuation . U.S. Holstein

\section{Introduction}

Changes in sires' predicted transmitting ability (PTA), which is half of the estimated breeding value, from the first to second crop of daughters evaluation have been a credibility concern to the dairy industry. A sire's initial progeny evaluation, based on the first crop of daughters, should be an unbiased estimate of later evaluations based on first and additional second crop daughters. Some changes in PTA are expected due to additional daughter information. Selective reporting and misidentification of daughters could also result in larger changes than expected. The former computing limitations resulted in the usage of 
only basic pedigrees, whereas deeper pedigrees were available. Parental selection, female selection, non-randomness in sire sampling, soundness of evaluation procedures (Bolgiano et al. 1979), and preferential treatment practices (Kuhn et al. 1994; Kuhn and Freeman 1995) have long concerned the dairy industry as well. Parental selection can be partially accounted for by using complete pedigrees (Kennedy and Sorensen 1988) and data on all candidates for selection (Henderson 1975). Although animal model evaluations account for differential mating of sires, preferential treatment to daughters of bulls or to potential bulls and dams cannot be accounted for (Kuhn et al. 1994). The model fitting random effects for preferential treatment was found to be ineffective in accounting for bias, since the accurate estimation of variances for preferential treatment is not feasible (Kuhn et al. 1999). Generally, preferential treatment is practiced in second or later evaluations due to an outstanding first record. In these cases, bias due to preferential treatment can be reduced by using only the first classification record of cows (Jamrozik and Schaeffer 1988). However, quantifying the amount of bias with field data is very difficult (Weigel and Lawlor 1994).

With regard to type traits, changes can occur due to reclassification. This implies that popular bulls are put at a disadvantage when the second crop of daughters, which have not yet been reclassified, enter the evaluation (Lohuis and Schaeffer 1995). The disadvantage is greater if the reclasses are to higher scores only, as in Canada, and if the mates were reclassified more than the average. Treating type traits as longitudinal (Uribe et al. 2000; Tsuruta et al. 2004) can potentially improve the accuracy of the evaluations; however, it is limited by only higher later scores in the Canadian system and few later scores in the US system. Improper accounting for heterogeneity of variances across subclasses, inaccurate age and stage of lactation adjustment factors, differences between registered and grade cows, and variation among classifiers' choice could be other identified sources of bias (Schaeffer et al. 1978; Powell and Norman 1986; Bonaiti et al. 1993; Togashi et al. 2004). Although many studies investigated the causes of changes in PTA for milk, fat, and protein from first to second crop evaluations, few studies looked at changes in the predicted transmitting ability for types (PTATs). The objective of the present study was to find ways of reducing changes of sires' PTA for final score from first to second crop evaluations.

\section{Materials and methods}

Data

Conformation final scores of Holsteins were obtained from the Holstein Association USA, Inc. The description of the classification system is available at http://www.holsteinusa. com/programs_services/classification.html. PTATs were estimated from two overlapping datasets: final scores recorded up to 2001 (D01) and records taken up to 2005 (D05). D01 comprised 7.7 million records from 4.6 million cows and D05 comprised 4 million records from 5.1 million cows.

Figure 1 illustrates the distribution of records as a function of year of classification. There are fewer numbers of records in the most recent years of classification because very few animals had a chance to reclassify. The two registry status groups of cows comprise registered ones, meeting the requirements of the breed association and recorded in the herdbook of the association, and grade, sired by AI proven bulls, not registered due to ineligible dam, usually maintained in commercial farms, and used for progeny testing. The proportion of grade cows has increased gradually from $12 \%$ in 1980 to $37 \%$ in 2005 . The percentage of records from grade cows also increased over the same period to 40 in 2005 (Fig. 1). Figure 2 shows the distribution of the mean final score in groups of cows
Fig. 1 Distribution of the number of records by classification year in cow groups

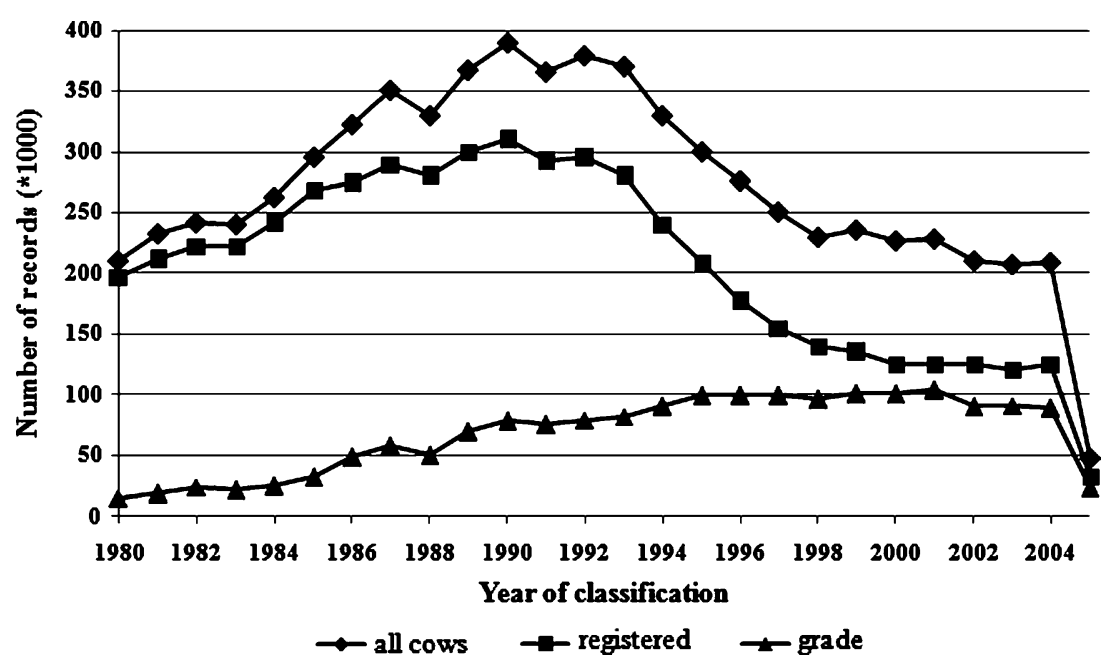


Fig. 2 Distribution of the mean final scores by classification year in cow groups

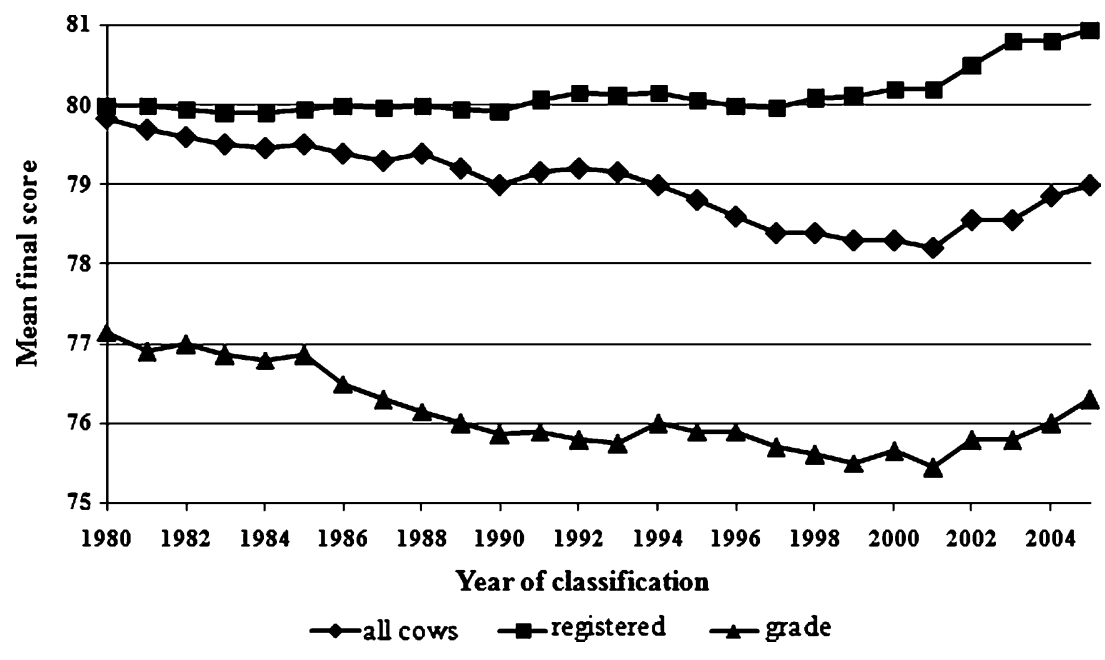

by year of classification. The mean final score was maximum (80.1) in 1973, minimum (78.1) in 2002, and the average was 79.2. Registered cows had a higher mean final score (80.0) than grade cows (76.0) across all classification years.

\section{Pedigrees}

Table 1 characterizes the pedigree files used with the D01 and D05 datasets. When the animal model evaluations for the type traits were initiated in 1991, nearly all cows were registered and nearly all grade cows had no dam information. To decrease the computing time, only pedigrees of registered cows were used. Over time, the percentage of grade cows increased dramatically and many of them had pedigrees. Following the amendments made for the purpose of the present study, a substantial improvement of parentage tracing can be observed.

Tables 2 and 3 refine the description of amendments to the pedigree across datasets and gender of parents whose pedigrees were amended.

Statistical analysis

\section{Variance component estimation}

Variance components were estimated from three subsets of D05 sampled randomly to include 50,000 records in each subset. Subset A included final score records from 1993 to 1996, subset B from 1997 to 2000, and subset C from 2001 to 2004.
Table 1 Characteristics of original and updated pedigrees for $\mathrm{D} 01^{\mathrm{a}}$ and $\mathrm{D} 05^{\mathrm{a}}$ as used in the genetic analyses
${ }^{a}$ D01: scores recorded up to 2001; D05: scores recorded up to 2005

\begin{tabular}{|c|c|c|c|c|c|}
\hline & \multirow[t]{2}{*}{ Total no. } & \multicolumn{4}{|c|}{ No. of parents known } \\
\hline & & Both & Sire only & Dam only & Both unknown \\
\hline \multicolumn{6}{|c|}{ Original pedigree D01 } \\
\hline Animals & $5,993,207$ & $3,742,249$ & 991,273 & 268 & $1,259,417$ \\
\hline Sires & 177,624 & 174,319 & 1,072 & 268 & 1,965 \\
\hline Dams & $2,640,721$ & $1,271,700$ & 111,569 & 0 & $1,257,452$ \\
\hline \multicolumn{6}{|l|}{ D05 } \\
\hline Animals & $6,606,175$ & $4,082,433$ & $1,157,141$ & 279 & $1,366,322$ \\
\hline Sires & 188,988 & 185,610 & 1,117 & 279 & 1,982 \\
\hline Dams & $2,889,054$ & $1,389,893$ & 134,821 & 0 & $1,364,340$ \\
\hline \multicolumn{6}{|c|}{ Updated pedigree D01 } \\
\hline Animals & $6,885,753$ & $5,704,276$ & $1,080,000$ & 2,786 & 98,691 \\
\hline Sires & 271,342 & 267,223 & 188 & 4 & 3,927 \\
\hline Dams & $3,628,177$ & $3,319,152$ & 211,479 & 2,782 & 94,764 \\
\hline \multicolumn{6}{|l|}{ D05 } \\
\hline Animals & $7,561,587$ & $6,171,764$ & $1,260,822$ & 6,010 & 122,991 \\
\hline Sires & 285,850 & 280,758 & 233 & 4 & 4,855 \\
\hline Dams & $3,961,039$ & $3,585,311$ & 251,586 & 6,006 & 118,136 \\
\hline
\end{tabular}


Table 2 Number of parents whose pedigrees were amended across gender and datasets ${ }^{\mathrm{a}}$ in particular classes of parentage information change

scores recorded up to 2001

\begin{tabular}{|c|c|c|c|c|c|}
\hline \multicolumn{2}{|c|}{ Class of parentage information change } & \multicolumn{2}{|c|}{ No. of dams } & \multicolumn{2}{|c|}{ No. of sires } \\
\hline From & To & D01 & D05 & D01 & D05 \\
\hline Only sire & Both & 491 & 491 & 925 & 927 \\
\hline Only dam & Both & 0 & 0 & 254 & 269 \\
\hline None & Both & $1,159,847$ & $1,250,332$ & 1,818 & 1,833 \\
\hline None & Only sire & 84,523 & 96,914 & 0 & 0 \\
\hline None & Only dam & 2,443 & 4,836 & 0 & 0 \\
\hline
\end{tabular}

While the official statistical model is similar to that in Misztal et al. (1993), the most important differences in this paper are the lack of herd by sire interaction, which is an artificial effect to reduce the PTA of natural sires, and the stage of lactation by time. Adding these effects in the current study did not make noticeable differences for the purpose of this study.

Different single-trait (ST) and multiple-trait (MT) animal models were used to estimate variances in the current study. The reference ST model was defined as follows:

$\mathrm{y}_{\mathrm{ijklmn}}=\mathrm{HYSC}_{\mathrm{i}}+\mathrm{Age}_{\mathrm{j}}+\mathrm{S}_{\mathrm{k}}+\mathrm{R}_{\mathrm{l}}+\mathrm{a}_{\mathrm{m}}+\mathrm{p}_{\mathrm{m}}+\mathrm{e}_{\mathrm{ijk} k \mathrm{mn}}$

where:

$\mathrm{y}_{\mathrm{ijk} k \mathrm{mn}} \quad$ Final score

$\mathrm{HYSC}_{\mathrm{i}}$ Fixed effect of the ith management group (herdyear-season-classifier)

Age $_{j} \quad$ Fixed effect of the jth age-year group at classification

$\mathrm{S}_{\mathrm{k}} \quad$ Fixed effect of the kth stage of lactation at classification

$\mathrm{R}_{1} \quad$ Fixed effect of registry status ( $\mathrm{l}=1$ for registered animals and 2 for grade animals)

$\mathrm{a}_{\mathrm{m}} \quad$ Additive genetic random effect of animal $\mathrm{m}$

$\mathrm{p}_{\mathrm{m}} \quad$ Random permanent environment effect of cow $\mathrm{m}$.

Age and stage-of-lactation groups were defined in twomonth steps within parities 1 to 3 .

Unknown parent groups (UPGs) were defined based on every other birth year starting from 1972. Table 3 shows the total numbers of dams and sires with UPGs starting from birth

Table 3 Number of sires and cows occurring as parents but without pedigree information in original and updated pedigree files for the two datasets $^{\mathrm{a}}$

\begin{tabular}{llllll}
\hline $\begin{array}{l}\text { No. of parents with no } \\
\text { pedigree information }\end{array}$ & \multicolumn{2}{l}{ Original pedigree } & & \multicolumn{2}{l}{ Updated pedigree } \\
\cline { 2 - 3 } \cline { 6 - 6 } & D01 & D05 & & D01 & D05 \\
\hline Dams & 849,628 & 956,455 & & 91,924 & 115,187 \\
Sires & 24 & 33 & & 3,628 & 4,547 \\
\hline
\end{tabular}

${ }^{\mathrm{a}}$ D01: scores recorded up to 2001; D05: scores recorded up to 2005 year 1972. Amending pedigrees (for D05) reduced the number of dams for whom UPGs were created from 956,455 to 115,187 and increased the number of sires from 33 to 4,547.

The MT model that considered the final scores of registered and grade cows as two separate but correlated traits accounted for the same effects as the ST model, except that the registry status effect was omitted. Adjustment for heterogeneity of variances within management group was also considered in the models as in Weigel and Lawlor (1994). The EM-REML method was used for the (co)variance components estimation.

\section{Prediction of breeding values}

In the ST model, the variance ratios of additive genetic and permanent environment effects were set to 1.6 and 2.5 , respectively; this corresponds to a heritability of 0.31 and a repeatability of 0.80 . The decline from the first to second classification could have been caused by: (a) missing pedigrees of grade cows; (b) unequal genetic merits of different groups of unknown parents; (c) traits in registered and grade animals being different but correlated; (d) different records of a cow being different traits; and combinations of all four causes. The modifications to the ST model included the following:

1. SEPUPG - ST with separate UPGs for the first and second crop of daughters, common for both sexes within crop, original pedigree

2. SEPUPG-SD - ST with separate UPGs for sires and dams, original pedigree

3. ST-F - Restricting the records to first records, original pedigree, joint UPGs

4. ST-L - Restricting the records to last records, original pedigree, joint UPGs

5. ST-PED - Inclusion of additional pedigrees for dams with missing parentage, joint UPGs

6. ST-PED-SUPG-SD - Additional pedigrees plus separate UPGs for sires and dams

7. ST-PED-F - Additional pedigrees plus using only first records, joint UPGs

8. ST-PED-L - Additional pedigrees plus using only last records, joint UPGs 
Table 4 Estimates of variance components and their ratios from single-trait (ST) models

\begin{tabular}{llll}
\hline Parameter $^{\mathrm{a}}$ & Subset $^{\mathrm{b}}$ & Subset B $^{\mathrm{c}}$ & Subset C \\
\hline$\sigma^{2}{ }_{a}$ & 4.20 & 4.00 & 3.30 \\
$\sigma^{2}{ }_{p}$ & 6.30 & 6.20 & 7.10 \\
$\sigma^{2}{ }_{e}$ & 2.80 & 2.50 & 2.30 \\
$h^{2}$ & 0.31 & 0.31 & 0.26 \\
$r^{2}$ & 0.79 & 0.80 & 0.82 \\
\hline
\end{tabular}

${ }^{\mathrm{a}} \sigma_{a}^{2}-$ additive genetic variance, $\sigma_{p}^{2}-$ permanent environment effect variance, $\sigma_{e}^{2}$-random residual variance, $h^{2}$ - heritability, $r^{2}$ - repeatability

${ }^{\mathrm{b}}$ Subset of data from 1993 to 1996

${ }^{\mathrm{c}}$ Subset of data from 1997 to 2000

${ }^{\mathrm{d}}$ Subset of data from 2001 to 2004

9. MT - Multiple-trait model assuming final scores of registered and grade cows are two separate correlated traits, original pedigree, joint UPGs

Sires born in recent years were expected to have their initial evaluation, based on the first crop of daughters only, by 2001, and those returning to service were expected to have their later evaluations, based on the first and additional second crop of daughters, by 2005. Thus, for common sires in D01 and D05, the PTATs computed using D01 were considered to be first crop evaluations (PTAT-01) and those predicted using D05 were second crop evaluations (PTAT-05). All PTATs were adjusted to the genetic base of all evaluated cows born in 1995 and compared for the stability of genetic evaluations from the first to second crop evaluation. The genetic base of cows in 1995 means that all PTATs were shifted so that the PTAT of a cow born in 1995 averaged 0. PTAT change was calculated as the difference between base adjusted PTAT-01 and PTAT-05.
PTAT changes were calculated for two sets of sires: 'ALL' including all of the sires with daughters in both D01 and D05 and 'SELECT' comprising 145 sires with 40 to 100 daughters in D01 and $\geq 200$ daughters in D05.

\section{Results and discussion}

Estimates of (co)variances and heritability

Table 4 shows the variance components estimated with the ST model using the three subsets of data. Additive genetic variance estimates decreased over time from 1993 to 2004 . A larger decrease was observed from 1997 to 2004 than from 1993 to 1997. This decrease may be due to selection and increased numbers of grade cows, which have limited pedigree information in recent years, as described by Tsuruta et al. (2002). Sorensen et al. (2001) also observed a similar pattern in additive genetic variance in recent years and reported that increased inbreeding and linkage disequilibrium are responsible for the observed downward trend in additive genetic variance. The reduction in the additive genetic variance might also be due to increased selection pressure on the final score or other correlated traits in recent years (Tsuruta et al. 2004).

Estimates of the residual variance decreased from subset A to subset C. Permanent environmental variance estimated from subset $\mathrm{C}$ was higher than from the other two subsets of data. Heritability estimates from subsets A and B were similar (0.31), but were reduced $(0.26)$ in subset $\mathrm{C}$. The differences between variances estimated from different subsets of data may also be due to changes in the structure of field data, i.e., changing the definition of final scores or changes in the base definition.

Table 5 shows (co)variance components estimated with the MT model. Changes in the estimates of variance

Table 5 Estimates of (co)variances and their ratios from multiple-trait (MT) animal models

\begin{tabular}{|c|c|c|c|c|c|c|c|}
\hline \multirow[t]{2}{*}{ Parameter $^{\mathrm{a}}$} & \multirow[t]{2}{*}{ Animal type } & \multicolumn{2}{|l|}{ Subset $A^{b}$} & \multicolumn{2}{|l|}{ Subset $B^{c}$} & \multicolumn{2}{|l|}{ Subset $C^{\mathrm{d}}$} \\
\hline & & Registered & Grade & Registered & Grade & Registered & Grade \\
\hline \multirow[t]{2}{*}{$\sigma_{a}^{2}$} & Registered & 4.44 & 2.80 & 4.24 & 2.72 & 3.72 & 2.41 \\
\hline & Grade & 2.80 & 3.25 & 2.72 & 2.92 & 2.41 & 2.65 \\
\hline$\sigma_{p}^{2}$ & & 6.02 & 7.21 & 5.51 & 7.99 & 5.97 & 8.90 \\
\hline$\sigma_{e}^{2}$ & & 2.81 & 3.55 & 2.51 & 2.81 & 2.32 & 2.47 \\
\hline$h^{2}$ & & 0.33 & 0.23 & 0.35 & 0.21 & 0.31 & 0.19 \\
\hline$r^{2}$ & & 0.79 & 0.75 & 0.80 & 0.80 & 0.81 & 0.82 \\
\hline$r_{\text {(registered, grade) }}$ & & 0.74 & & 0.77 & & 0.77 & \\
\hline
\end{tabular}

${ }^{\mathrm{a}} \sigma_{a}^{2}$ - additive genetic variance, $\sigma_{p}^{2}$ - permanent environment effect variance, $\sigma^{2}{ }_{e}$ - random residual variance, $h^{2}-$ heritability, $r^{2}-$ repeatability

${ }^{\mathrm{b}}$ Subset of data from 1993 to 1996

${ }^{\mathrm{c}}$ Subset of data from 1997 to 2000

${ }^{\mathrm{d}}$ Subset of data from 2001 to 2004 
components across the three subsets of data were similar to those observed with the ST model. The additive genetic variances of registered cows were higher. This may be due to more pedigree information being available. However, the estimated residual and permanent environment variances of registered cows were lower in all three time periods. The lower residual variance for registered cows might be due to better management, which apparently improves in grades as the $\sigma_{e}^{2}$ difference tends to vanish. In the end, the heritability of the final score for registered cows is greater than for grade cows across the three subsets of data. Repeatability estimates of registered and grade cows were similar over time. The genetic correlation between registered and grade cows was moderately high (0.77) and constant over time. Even though the variances altered over time, the variances estimated from subset B are similar to those reported in the literature (Short and Lawlor 1992). Subset B also represents the most recent data common to both D01 and D05, hence, the variances estimated from subset B (i.e., 1997-2000) were utilized in the present study.

\section{Predicted transmitting abilities}

The base adjusted PTAT- 01 and PTAT- 05 are summarized in Table 6 for ALL $(177,451)$ and SELECT (145) sires across all models. For sires with no change in the number of progeny from the first to second crop evaluations, the mean PTAT change was less than 0.05 for most models and, correspondingly, the correlation between PTAT-01 and PTAT-05 $\left(r_{01}, 05\right)$ was almost unity. Only a few sires had more daughters added in the second crop evaluations. The correlation between PTAT-01 and PTAT-05 was 0.77 in the ST model and this increased to 0.82 in the ST-PED-SUPGSD model for SELECT sires.

\section{PTAT changes}

Table 7 summarizes the means of changes in sire PTATs from the first to second crop. For ALL sires, the mean PTAT change ranges from -0.03 to 0.10 among the different models analyzed. For SELECT sires, the PTAT change ranged from -1.77 to 0.65 in the ST model with a mean PTAT change of -0.33 . Judging by the mean (Table 7), the distribution of PTAT changes for SELECT sires with ST is negatively shifted. Adding separate UPGs to second crop daughters (SEPUPG) increased the mean changes to -0.38 . Distinguishing between UPGs for sires and dams (SEPUPG-SD) slightly reduced the changes to -0.29 , yet, separate UPGs for sires had very few contributing animals with sire missing but dam present (Table 3). Restriction of the records to only the first classification records of cows (ST-F) reduced the mean PTAT change to -0.20 . The decrease is mainly due to increased merit of all of the sires, including the

Table 6 Averages $^{\mathrm{a}}$ of predicted transmitting ability for types (PTAT) for two datasets and studied models

\begin{tabular}{|c|c|c|c|c|c|c|}
\hline \multirow{2}{*}{\multicolumn{2}{|c|}{ Models $^{\mathrm{b}}$}} & \multicolumn{2}{|c|}{$\operatorname{ALL}^{\mathrm{c}}(n=177,451)$} & \multicolumn{3}{|c|}{$\operatorname{SELECT}^{\mathrm{c}}(n=145)$} \\
\hline & & PTAT- $01^{d}$ & PTAT- $05^{\mathrm{d}}$ & PTAT- $01^{\mathrm{d}}$ & PTAT- $05^{\text {d }}$ & $r_{(01,05)}{ }^{\mathrm{e}}$ \\
\hline \multicolumn{2}{|l|}{ ST } & -1.29 & -1.32 & 1.23 & 0.90 & 0.77 \\
\hline \multicolumn{2}{|c|}{ SEPUPG } & -1.29 & -1.33 & 1.20 & 0.89 & 0.77 \\
\hline \multicolumn{2}{|c|}{ SEPUPG-SD } & -1.31 & -1.34 & 1.28 & 0.99 & 0.78 \\
\hline \multicolumn{2}{|c|}{ ST-F } & -1.20 & -1.19 & 1.27 & 1.06 & 0.81 \\
\hline \multicolumn{2}{|c|}{ ST-L } & -1.33 & -1.23 & 1.16 & 1.03 & 0.80 \\
\hline \multicolumn{2}{|c|}{ ST-PED } & -1.61 & -1.61 & 1.32 & 1.04 & 0.78 \\
\hline \multicolumn{2}{|c|}{ ST-PED-SUPG-SD } & -1.69 & -1.67 & 1.41 & 1.29 & 0.82 \\
\hline \multicolumn{2}{|c|}{ ST-PED-F } & -1.51 & -1.47 & 1.38 & 1.25 & 0.82 \\
\hline \multicolumn{2}{|c|}{ ST-PED-L } & -1.56 & -1.53 & 1.39 & 1.21 & 0.81 \\
\hline \multirow[t]{2}{*}{ MT } & Registered & -1.54 & -1.58 & 1.12 & 0.71 & 0.75 \\
\hline & Grade & -0.60 & -0.56 & 1.08 & 0.84 & 0.80 \\
\hline
\end{tabular}

${ }^{\mathrm{a}}$ Standard errors of PTAT- $01^{\mathrm{d}}$ and PTAT- $05^{\mathrm{e}}$ are 0.001 to 0.003 for ALL ${ }^{\mathrm{c}}$ sires and 0.05 to 0.06 for SELECT ${ }^{\mathrm{c}}$ sires

${ }^{\mathrm{b}}$ ST - single-trait repeatability animal model; SEPUPG - ST with separate UPGs for first and second crop daughters; SEPUPG-SD - ST with separate UPGs for sires and dams; ST-F - ST with only the first classification record of cows; ST-L - ST with only the last classification record of cows; ST-PED ST with additional pedigree; ST-PED-SUPG-SD - ST-PED with separate UPGs for sires and dams; ST-PED-F - ST-PED with only the first classification record of cows; ST-PED-L - ST-PED with only the latest classification record of cows; MT - multiple-trait animal model

${ }^{\mathrm{c}}$ ALL - all of the sires with daughters in both D01 and D05; SELECT - sires with 40 to 100 daughters classified by 2001 (D01) and $\geq 200$ daughters classified by 2005 (D05)

${ }^{\mathrm{d}}$ PTAT-01 - average first crop PTATs of sires; PTAT-05 - average second crop PTATs of sires

${ }^{\mathrm{e}} r_{(01,05)}-$ correlation between the first and second crop PTATs 
Table 7 Estimates $^{\mathrm{a}}$ of PTAT changes from first to second crop evaluations for different models

\begin{tabular}{|c|c|c|c|c|c|c|c|}
\hline \multirow{2}{*}{\multicolumn{2}{|c|}{ Models ${ }^{\mathrm{b}}$}} & \multicolumn{3}{|c|}{$\operatorname{ALL}(n=177,451)^{\mathrm{c}}$} & \multicolumn{3}{|c|}{ SELECT $(n=145)^{\mathrm{c}}$} \\
\hline & & Mean & Min. & Max. & Mean & Min. & Max. \\
\hline \multicolumn{2}{|l|}{ ST } & -0.03 & -1.77 & 2.19 & -0.33 & -1.77 & 0.65 \\
\hline \multicolumn{2}{|c|}{ SEPUPG } & -0.04 & -1.82 & 2.19 & -0.38 & -1.82 & 0.60 \\
\hline \multicolumn{2}{|c|}{ SEPUPG-SD } & -0.03 & -1.72 & 2.27 & -0.29 & -1.72 & 0.73 \\
\hline \multicolumn{2}{|c|}{ ST-F } & 0.00 & -1.66 & 2.23 & -0.20 & -1.41 & 0.85 \\
\hline \multicolumn{2}{|c|}{ ST-L } & 0.10 & -1.55 & 2.29 & -0.13 & -1.40 & 0.88 \\
\hline \multicolumn{2}{|c|}{ ST-PED } & 0.00 & -1.78 & 3.85 & -0.28 & -1.78 & 0.65 \\
\hline \multicolumn{2}{|c|}{ ST-PED-SUPG-SD } & 0.03 & -2.14 & 4.29 & -0.12 & -1.47 & 0.81 \\
\hline \multicolumn{2}{|c|}{ ST-PED-F } & 0.04 & -2.46 & 2.63 & -0.14 & -1.29 & 0.85 \\
\hline \multicolumn{2}{|c|}{ ST-PED-L } & 0.02 & -2.67 & 2.18 & -0.18 & -1.46 & 0.77 \\
\hline \multirow[t]{2}{*}{ MT } & Registered & -0.04 & -1.86 & 5.85 & -0.40 & -1.85 & 0.78 \\
\hline & Grade & 0.04 & -1.54 & 1.85 & -0.24 & -1.39 & 0.58 \\
\hline
\end{tabular}

${ }^{\mathrm{a}}$ Standard errors of the means are all 0.00 for ALL sires and 0.03 to 0.04 for SELECT sires

${ }^{\mathrm{b}}$ ST - single-trait repeatability animal model; SEPUPG - ST with separate UPGs for first and second crop daughters; SEPUPG-SD - ST with separate UPGs for sires and dams; ST-F - ST with only the first classification record of cows; ST-L - ST with only the last classification record of cows; STPED - ST with additional pedigree; ST-PED-SUPG-SD - ST-PED with separate UPGs for sires and dams; ST-PED-F - ST-PED with only the first classification record of cows; ST-PED-L - ST-PED with only the latest classification record of cows; MT - multiple-trait animal model

${ }^{\mathrm{c}}$ ALL - all of the sires with daughters in both D01 and D05; SELECT sires with 40 to 100 daughters classified by 2001 (D01) and $\geq 200$ daughters classified by 2005 (D05)

old sires. This reduced the merit of dams of second crop daughters and increased the merit of second crop evaluations of sires. When only the last records were used (ST-L), the mean PTAT change was further reduced to -0.13 as later records are, on average, higher than the first; the first crop will only have later records when the second crop is coming, resulting in inflated second crop evaluations.

The inclusion of additional pedigrees for dams with missing parentage (ST-PED) reduced the bias $(-0.28)$ by very little compared to ST. Allowing separate UPGs for sires and dams together with additional pedigrees (STPED-SUPG-SD) greatly reduced the mean PTAT change to -0.12 . The addition of pedigrees increased the number of sires contributing to UPGs from 33 to 4,547 (in D05) and allowed more accurate estimations of genetic groups for sires (Table 3). Because most of the contributions to these UPGs are from maternal grand sires, these UPGs act as a proxy for the average merit of dams of test bulls. The results of the MT model showed that the mean PTAT change was larger for registered cows $(-0.40)$ than for grade cows $(-0.24)$, although the changes are large. Smaller changes in grade cows' PTATs could be due to the lower additive genetic variances in grades.
Percentage of sires showing PTAT changes

The percentage distributions of the SELECT sires, divided into three categories according to PTAT change, are given in Table 8. The percentage of sires showing decline were $74.5 \%$ with the ST model, of which $27.6 \%$ were showing a change between -1 to -0.5 and $6.9 \%$ showing change $>-1$. The percentage of sires showing bias was $78.6 \%$ when allowing separate UPGs for second crop daughters (SEPUPG) and was slightly reduced (72.4\%) when allowing separate UPGs for sires (SEPUPG-SD). This small change in percentage may be due to random chance, as there is no observable difference between the parent averages of these sires among the above three models. Using only the first classification records of cows (ST-F) reduced the percentage of sires showing bias to $64.8 \%$, of which only $20.7 \%$ were showing a bias of high magnitude, i.e., below -0.5 . Considering only the most recent classification records of cows (ST-L) further reduced the percentage of sires showing bias beyond -0.5 to $17.3 \%$. The changes with the MT model were similar to in the ST model, suggesting only a minor influence of grade status on PTAT changes.

Using additional pedigrees (ST-PED) slightly reduced the percentage of sires showing bias from $74.5 \%$ to $72.1 \%$, of which $32.0 \%$ were showing a change below -0.5 . Only a

Table 8 Percentage of SELECT ${ }^{\mathrm{a}}$ sires $(n=145)$ showing decline in PTAT from the first to second crop for different models

\begin{tabular}{|c|c|c|c|c|c|}
\hline \multirow{2}{*}{\multicolumn{2}{|c|}{ Models ${ }^{\mathrm{b}}$}} & \multicolumn{4}{|c|}{$\%$ sires showing bias between } \\
\hline & & 0 to -0.5 & -0.5 to -1 & $>-1$ & Total \\
\hline \multicolumn{2}{|l|}{ ST } & 40.0 & 27.6 & 6.9 & 74.5 \\
\hline \multicolumn{2}{|c|}{ SEPUPG } & 40.7 & 30.3 & 7.6 & 78.6 \\
\hline \multicolumn{2}{|c|}{ SEPUPG-SD } & 41.4 & 24.8 & 6.2 & 72.4 \\
\hline \multicolumn{2}{|c|}{ ST-F } & 44.1 & 16.6 & 4.1 & 64.8 \\
\hline \multicolumn{2}{|c|}{ ST-L } & 40.0 & 14.5 & 2.8 & 57.3 \\
\hline \multicolumn{2}{|c|}{ ST-PED } & 40.1 & 25.9 & 6.1 & 72.1 \\
\hline \multicolumn{2}{|c|}{ ST-PED-SUPG-SD } & 44.2 & 8.8 & 3.4 & 56.4 \\
\hline \multicolumn{2}{|c|}{ ST-PED-F } & 42.2 & 13.6 & 3.4 & 59.2 \\
\hline \multicolumn{2}{|c|}{ ST-PED-L } & 45.6 & 13.6 & 4.1 & 63.3 \\
\hline & Registered & 42.8 & 24.8 & 11.7 & 79.3 \\
\hline & Grade & 46.9 & 20.0 & 3.5 & 70.4 \\
\hline
\end{tabular}

${ }^{a}$ SELECT - sires with 40 to 100 daughters classified by 2001 (D01) and $\geq 200$ daughters classified by 2005 (D05)

${ }^{\mathrm{b}}$ ST - single trait repeatability animal model; SEPUPG - ST with separate UPGs for first and second crop daughters; SEPUPG-SD - ST with separate UPGs for sires and dams; ST-F - ST with only the first classification record of cows; ST-L - ST with only the last classification record of cows; STPED - ST with additional pedigree; ST-PED-SUPG-SD - ST-PED with separate UPGs for sires and dams; ST-PED-F - ST-PED with only the first classification record of cows; ST-PED-L - ST-PED with only the latest classification record of cows; MT - multiple-trait animal model 
slight improvement was possibly due to low connectivity through those dams and possibly larger misidentifications. The percentage of sires showing changes below -0.5 was reduced to $17.7 \%$ by ST-PED-L and to $17.0 \%$ by ST-PED-F. The accuracy of evaluation methods based on the first classification records only depends on how accurate the classifiers are in judging a cow at a young age. Restricting data to only the most recent classification reduces the bias but still retains it in the second crop and may actually cause even more bias than reducing it. Using single records per cow would also reduce the participation in the classification program.

The percentage of sires showing bias was smallest (56.4\%) with separate UPGs for sires and dams together with additional pedigrees (ST-PED-SUPG-SD). Only $12.2 \%$ of sires showed a change below -0.5 .

\section{Conclusions}

Declines in the predicted transmitting ability (PTA) for final score from the first to second crop of daughters were caused indirectly by increased fraction of grade cows and, subsequently, inadequate accounting for the merit of mates. Bias is not reduced by considering separate unknown parent groups (UPGs) for first and second crop daughters, additional pedigrees alone, or by considering differences in registered and grade animals. Use of the first records reduces the bias but also the accuracy of evaluations. Using only the last records reduces the decline but is less efficient with amended pedigrees. Reduction of the decline requires separate UPGs for sire and dams, along with additional pedigrees for dams.

Open Access This article is distributed under the terms of the Creative Commons Attribution Noncommercial License which permits any noncommercial use, distribution, and reproduction in any medium, provided the original author(s) and source are credited.

\section{References}

Bolgiano DC, Van Vleck LD, Everett RW (1979) Fluctuations in sire evaluations. J Dairy Sci 62:760-767
Bonaiti B, Boichard D, Barbat A, Mattalia S (1993) Problems arising with genetic trend estimation in dairy cattle. In: Proceedings of the Open Session of the Interbull Annual Meeting, Aarhus, Denmark, August 1993. Bulletin No. 8, pp 65-72

Henderson CR (1975) Best linear unbiased estimation and prediction under a selection model. Biometrics 31:423-447

Jamrozik J, Schaeffer LR (1988) Evaluation of dairy cattle for final class using animal models. Can J Anim Sci 68:639-645

Kennedy BW, Sorensen DA (1988) Properties of mixed model methods for prediction of genetic merit. In: Proceedings of the Second International Conference on Quantitative Genetics, Raleigh, North Carolina, USA, May/June 1987, pp 91-103

Kuhn MT, Freeman AE (1995) Biases in predicted transmitting abilities of sires when daughters receive preferential treatment. J Dairy Sci 78:2067-2072

Kuhn MT, Boettcher PJ, Freeman AE (1994) Potential biases in predicted transmitting abilities of females from preferential treatment. J Dairy Sci 77:2428-2437

Kuhn MT, Freeman AE, Fernando RL (1999) Approaches investigated to correct for preferential treatment. J Dairy Sci 82:181-190

Lohuis M, Schaeffer LA (1995) Prelude's type evaluation: facts. Holstein Journal. Available online at: http://cgil.uoguelph.ca/pub/ articles/prelude2.html. Accessed 17 October 2010

Misztal I, Lawlor TJ, Short TH (1993) Implementation of single- and multiple-trait animal models for genetic evaluation of Holstein type traits. J Dairy Sci 76:1421-1432

Powell RL, Norman HD (1986) Genetic and environmental differences between registered and grade Holstein cows. J Dairy Sci 69:2897-2907

Schaeffer LR, Hunt MS, Burnside EB (1978) Evaluation of HolsteinFriesian dairy sires for conformation of their daughters. Can J Anim Sci 58:409-417

Short TH, Lawlor TJ (1992) Genetic parameters of conformation traits, milk yield, and herd life in Holsteins. J Dairy Sci 75:19871998

Sorensen DA, Fernando R, Gianola D (2001) Inferring the trajectory of genetic variance in the course of artificial selection. Genet Res 77:83-94

Togashi K, Lin CY, Yokouchi K (2004) Overview of genetic evaluation in dairy cattle. Anim Sci J 75:275-284

Tsuruta S, Misztal I, Klei L, Lawlor TJ (2002) Analysis of age-specific predicted transmitting abilities for final scores in Holsteins with a random regression model. J Dairy Sci 85:1324-1330

Tsuruta S, Misztal I, Lawlor TJ, Klei L (2004) Modeling final scores in US Holsteins as a function of year of classification using a random regression model. Livest Prod Sci 91:199-207

Uribe H, Schaeffer LR, Jamrozik J, Lawlor TJ (2000) Genetic evaluation of dairy cattle for conformation traits using random regression models. J Anim Breed Genet 117(4):247-259

Weigel KA, Lawlor TJ (1994) Adjustment for heterogeneous variance in genetic evaluations for conformation of United States Holsteins. J Dairy Sci 77:1691-1701 